\title{
A elaboração conceitual em química orgânica na perspectiva da semiótica Peirceana
}

\author{
Conceptual elaboration in organic chemistry \\ from the perspective of Peircean semiotics
}

Edson José Wartha ${ }^{1}$ • Daisy de Brito Rezende ${ }^{2}$

\begin{abstract}
Resumo: Este trabalho procura aproximar as Ciências Cognitivas da Semiótica de Peirce na tentativa de compreender as dificuldades apresentadas por estudantes na apropriação de processos de representação envolvidos na aprendizagem de conceitos relacionados à Química Orgânica. Busca-se, a partir do acompanhamento de disciplinas de Química Orgânica em cursos de graduação, identificar e interpretar processos cognitivos que envolvem percepção, interpretação e construção de representações estruturais a partir da semiótica de Peirce. Os resultados indicam que dificuldades de ensino e de aprendizagem em Química Orgânica não são devidas apenas a aspectos conceituais, mas, também, têm forte relação com os aspectos representacionais.
\end{abstract}

Palavras-chave: Ensino de química. Semiótica. Química orgânica. Representação do conhecimento. Linguagem.

\begin{abstract}
This study focuses on the contributions that the cross linking of Cognitive Sciences with Peircean Semiotics could bring for understanding students' difficulties in the representation processes in Organic Chemistry. The occurrence of perception processes, interpretation and building representations in Organic Chemistry teaching were identified and analyzed. Our results showed that Peircean Semiotics has positively contributed to the understanding of the conceptual elaboration processes in Organic Chemistry, especially regarding language acquisition. To summarise, we concluded that the difficulties involved in Organic Chemistry didactics are associated essentially with representational aspects, while the conceptual ones play a secondary role. These factors could be perceived even for undergraduate students, where it is supposed to be less relevant.
\end{abstract}

Keywords: Chemistry teaching. Semiotics. Organic chemistry. Knowledge representation. Language acquisition.

\footnotetext{
${ }^{1}$ Universidade Federal de Sergipe (UFS), Campus Universitário Prof. Alberto de Carvalho, Av. Vereador Olimpio Grande, s/n, CEP 49500000, Itabaiana, SE, Brasil. E-mail: <ejwartha@gmail.com>

${ }^{2}$ Departamento de Química Fundamental, Instituto de Química (IQ), Universidade de São Paulo (USP), São Paulo, SP, Brasil.
} 


\section{Introdução}

Neste estudo, buscou-se uma aproximação entre as Ciências Cognitivas e a Semiótica Peirceana, na tentativa de explicar as dificuldades apresentadas por sucessivas turmas de estudantes de graduação em disciplinas de Química orgânica, em várias Instituições de Ensino Superior (IES). A hipótese subjacente a esta abordagem é a de que esta perspectiva facilitaria interpretar como estudantes de cursos de graduação estabelecem a percepção, a relação e a conceituação sobre os sistemas simbólicos envolvidos durante o processo de elaboração conceitual na disciplina de química orgânica.

$\mathrm{Na}$ perspectiva deste trabalho, considera-se que o emprego de representações em Química constitui, por si mesmo, uma linguagem altamente estruturada, que deve ser aprendida pelos estudantes, para que possam compreender e expressar os conhecimentos nesse campo do conhecimento. Assim, alguns estudos têm mostrado que, em processos de aprendizagem, os alunos elaboram algum tipo de construção simbólica (imagens, figuras, esquemas e diagramas, por exemplo) com a finalidade de identificar e relacionar a informação e, desse modo, torná-la mais significativa. Kleinman, Griffin e Kerner (1987), por exemplo, sugerem que os alunos podem apresentar dificuldades em aprender Química devido a não estabelecerem relações entre os componentes conceituais e visuais (como imagens, esquemas, diagramas ou figuras mais adequadas para aquela determinada situação) do conhecimento apresentado a eles. Já, para Habraken (1996, 2004), o problema é que os aspectos conceituais e lógico-matemáticos têm sido favorecidos no ensino de Química em detrimento dos componentes visuais, parecendo haver, entre os professores, um consenso de que os signos (imagens, figuras, diagramas) amplamente empregados na comunicação do conhecimento químico, sejam meras ilustrações. Em raras situações, percebem-se, entre eles, abordagens didáticas que explorem as potencialidades de ferramentas - seja de visualização seja de quaisquer outras modalidades - que permitam ampliar o processo de percepção sobre aspectos representacionais em aulas de Química.

É importante frisar que o conhecimento não existe per se no texto, na figura, no diagrama ou na ilustração. Por intermédio destes meios, o que existe são manifestações linguísticas de conceituações. Assim, acredita-se que seja possível transmitir conhecimento por meio de uma imagem, da língua natural, da linguagem computacional, por exemplo, em que o transmitir é contextual, sendo o processo de construção próprio do sujeito. Na perspectiva da Semiótica Peirceana, a imagem não é construída pelo sujeito, ela é percebida, relacionada, para permitir a construção de um novo signo e, nesse caso, a apreensão do conceito. Para tanto, são necessários processos que permitam perceber, relacionar, organizar e representar esse conhecimento com maior ou menor grau de complexidade; e é, nesse ponto, que a Semiótica Peirceana se apresenta como um novo olhar para o processo de construção do conhecimento químico, que, acima de tudo, é permeado por signos. Em poucas palavras, pode-se dizer que aprender Química é aprender uma nova linguagem, associada a uma nova forma de pensar o mundo.

Na perspectiva da Semiótica Peirceana, a representação é vista como um conteúdo apreendido pelos sentidos, pela memória, pela imaginação, pelo pensamento, o que a caracteriza como a "Teoria geral dos signos" ou "Teoria geral das representações". Na concepção de Peirce (2005), signo é aquilo que representa algo para alguém, percebido sob algum de seus aspectos, ocupando o lugar de alguma outra coisa, em lugar do ente em si, ou seja, só se percebe aquilo que se está capacitado a interpretar. 
Para que o signo seja capaz de mediar o processo de produção de significados (interpretantes) aceitos por determinada comunidade científica, é preciso considerar os fatores relacionados ao intérprete (estudante): conhecimento dos conteúdos (perceber), regras e habilidade para estabelecer relações entre signo-referente e signo-interpretante (relacionar) para poder atribuir significados (conceituar). A Semiótica Peirceana apresenta um potencial teórico muito interessante para que se possa, também, discutir a questão das representações do conhecimento químico, sobretudo hoje, no ambiente das múltiplas linguagens. e, sobretudo, dos ambientes virtuais.

Assim, pode-se considerar o professor como mediador do discurso; os estudantes como a comunidade discursiva; e as representações semióticas como ferramentas de ensino e aprendizagem; e, ainda, que, na sala de aula, os professores e estudantes geram um intercâmbio de ideias por meio da linguagem, que incorpora uma simbologia particular, criando, assim, um sistema de representações. Esse sistema, linguístico e pictórico, é usado na construção de um discurso pedagógico vinculado a uma disciplina, considerando que a linguagem química depende de um conhecimento prévio, construído e convencionado. Desse modo, pode-se sintetizar a relação entre a tríade semiótica de Peirce (2005) na forma de uma tríade pedagógica que envolve o Perceber (primeiridade), a Relação (secundidade) e a Conceituação (terceiridade).

Em geral, na disciplina de química orgânica, as regras dependem do marco conceitual e da relevância da ontologia no processo de descrição do mundo físico para que seja possível raciocinar e agir sobre ele. Desse modo, a Semiótica Peirceana é uma forma de olhar o processo de elaboração conceitual em química orgânica e refletir sobre ele. Nesse olhar (Figura 1), a representação é vista como um processo mediado, dinâmico e sistêmico.

Figura 1. Modelo do processo de construção de significados na tríade pedagógica

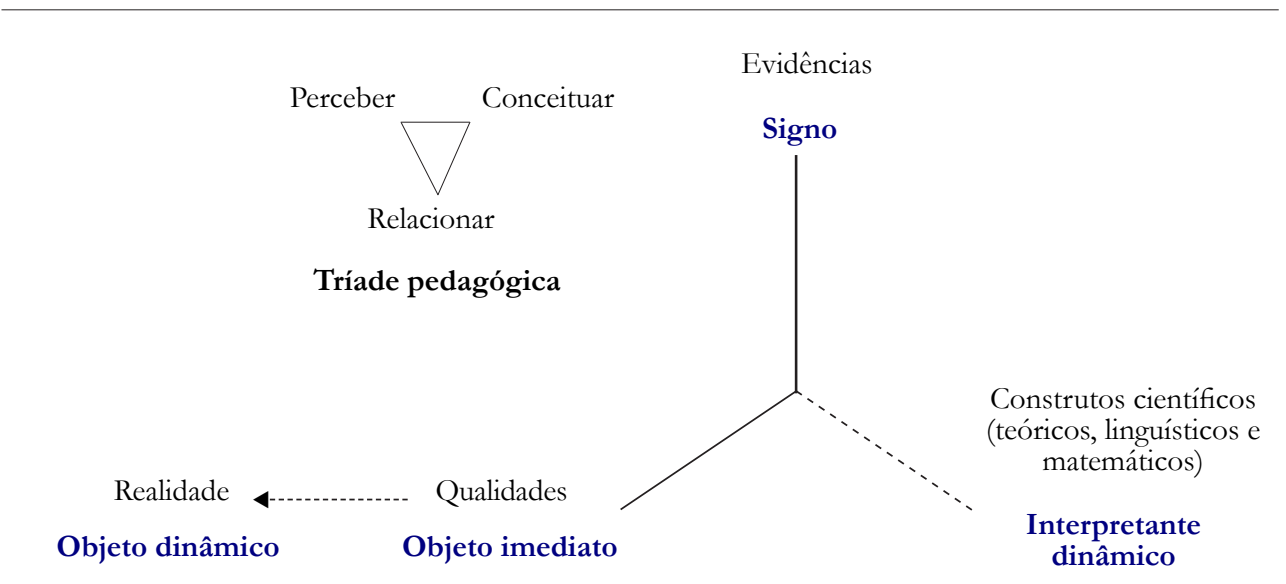

Fonte: adaptado de Souza (2012). 
Nesse modelo, é necessário destacar que o acesso aos entes químicos (objeto imediato) possui diferentes aspectos que só podem ser percebidos em partes, uma vez que não podem ser acessados em sua totalidade (objeto dinâmico). Dessa forma, a tríade semiótica proporciona a superação de alguns problemas epistemológicos e ontológicos relacionados à realidade dos entes químicos. O acesso aos entes químicos, na acepção da Semiótica Peirceana, é sempre um processo mediado e limitado pelo relativismo imposto pela própria natureza deles. As evidências empíricas - incluindo aquelas viabilizadas por instrumentos -, atuam como signos que evidenciam aspectos específicos e restritos dos objetos a que se referem. Deve-se considerar, ainda, que a proposição de uma teoria científica, por exemplo, envolve inúmeros momentos de primeiridade (perceber), secundidade (relacionar) e terceiridade (conceituar) que poderão levar a diferentes interpretantes dinâmicos (emocionais, energéticos e lógicos), cuja síntese intelectual, eventualmente, produzirá um consenso acerca de determinado interpretante lógico (conceito, lei ou teoria) que se acredita ser mais próximo do conhecimento cientificamente aceito (JORGE; REZENDE; WARTHA, 2013).

A dimensão educacional dos processos de ensino e aprendizagem de Química, que envolve a constante manipulação de fenômenos, símbolos e modelos, faz com que a habilidade de manejo e compreensão de diferentes sistemas sígnicos seja ponto crucial não só no processo de construção do conhecimento químico, mas, também, em seu processo de enculturação pelos alunos. No que se refere, mais especificamente, à questão da representação no Ensino de Química, Alex H. Johnstone, professor do Departamento de Química da Universidade de Glasgow, em diversos artigos (JOHNSTONE, 1982, 1993, 2000, 2010), foi um dos primeiros pesquisadores a propor um modelo para a representação do conhecimento químico, o qual subdivide em três diferentes níveis, associados segundo o notório triângulo de Johnstone (Figura 2). Essencialmente, o modelo de Johnstone propõe: um nível sensorial ou perceptivo (nível macroscópico), um nível molecular ou exploratório (nível submicroscópico), e um terceiro nível, o representacional (nível simbólico), que articulariam as dimensões do conhecimento químico.

Figura 2. Os três componentes básicos da "nova Química"

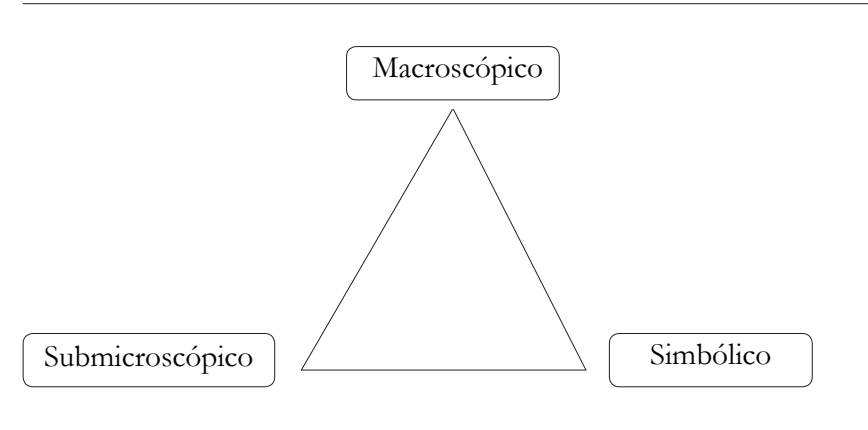

Fonte: adaptado de Johnstone (1993, 2000).

Nessas quatro décadas, o triângulo de Johnstone tem atraído uma série de seguidores, como, por exemplo, o grupo de pesquisa coordenado por Treagust, que tem publicado trabalhos concernentes à habilidade de modelização e sua relação com o nível de representação submicroscópico proposto por Johnstone (CHANDRASEGARAN; TREAGUST; MOCERINO, 
2007; CHITTLEBOROUGH; TREAGUST, 2007; TREAGUST; CHITTLEBOROUGH; MAMIALA, 2003). Nesses trabalhos, investigou-se o papel dos modelos físicos como instâncias mediais simbólicas no estabelecimento, entre estudantes (14 a 16 anos), de relações entre os níveis de representação macroscópicos, submicroscópicos e representacionais.

Há trabalhos que procuram modificar o modelo proposto por Johnstone, como é o caso daquele proposto por Rappoport e Ashkenazi (2008), que alteraram os níveis de representação de Johnstone para níveis de abstração; e o caso de Talanquer (2011), que propõe uma divisão entre o nível experimental (macroscópico/experiências) e o representacional (submicroscópico e simbólico/modelo e visualização).

Todavia, a partir de 2010, começam a surgir alguns estudos na literatura questionando o modelo de Johnstone, como é o caso do trabalho de Labarca (2010), que afirma haver equívocos filosóficos associados à confusão entre os planos de argumentação, ou os três níveis de representação, como proposto por Johnstone (1982, 1993, 2000, 2010). Para esse autor, Johnstone, em seu modelo, confunde o plano ontológico com os planos linguístico/conceitual e matemático. Para Labarca (2010), planos diferentes não poderiam estar representados como vértices em um mesmo triângulo, ou seja, como planos equivalentes. Esse autor argumenta que deve haver distinção entre o que se relaciona ao sujeito (itens linguísticos e conceituais, como conceitos, leis e teorias) e aquilo que se relaciona ao objeto (itens ontológicos, tais como entes químicos e propriedades). No plano ontológico, pode haver níveis distintos, tanto o nível macroscópico como o nível submicroscópico; enquanto o plano linguístico e conceitual pode abranger leis, descrições, teorias; e, um terceiro plano, o matemático, corresponder às manipulações matemáticas de itens linguísticos. As ontologias não podem ser extraídas automaticamente de um texto, de uma figura ou de um diagrama, por exemplo, uma vez que a ontologia obedece a um determinado processo de construção envolvendo, por exemplo, o consenso de uma comunidade científica.

Desse modo, acredita-se que a valorização dos aspectos de mediação (tríade pedagógica: perceber, relacionar e conceituar) em aulas de química orgânica poderá contribuir para a superação de algumas dificuldades metodológicas e epistemológicas relacionadas aos entes químicos (itens ontológicos), não apenas no que se refere à sua existência, mas, também, às suas consequências de asserção, de que a realidade molecular é a causa dos fenômenos, e não uma explicação para eles. Tal fato poderia ser mais bem compreendido na relação entre o objeto dinâmico e o objeto imediato, pois, de acordo com a Semiótica Peirceana, poder-se-ia afirmar ser essa a maneira por meio da qual um intérprete (estudante) acessa a realidade (objeto dinâmico). Como é possível perceber apenas parte do objeto através da mediação de signos, tem-se, apenas, uma percepção parcial (objeto imediato) dele (SANTAELLA, 2012).

Tal abordagem contribui para a compreensão da atividade científica como processo de permanente construção, interpretação e significação, influenciado pelo contexto. Dessa maneira, na perspectiva da Semiótica Peirceana, a percepção do processo de construção do conhecimento químico permite a superação de alguns problemas ontológicos relacionados à representação de entes químicos, como é o caso daquele apresentado pelo triângulo de Johnstone (Figura 2). Como, na perspectiva da semiótica, a realidade é mediada pelas interações entre signos (signo, objeto e interpretante), não há envolvimento de planos equivalentes de argumentação ou de representação: em outras palavras, o signo representa o objeto; o objeto determina o signo, e o interpretante é determinado, imediatamente, pelo signo e, mediatamente, pelo objeto. 
De acordo com Peirce (2005), o real, como interesse científico, encarna-se na figura de um objeto dinâmico externo à própria Ciência, funcionando como princípio regulador que atribui ao conhecimento sua coesão e permite sua apreensão pelos sujeitos. Ao mesmo tempo, porém, esse mesmo real expressa-se nos objetos imediatos veiculados pela representação. Para Peirce, a verdade vai se revelando aos poucos no processo científico de descoberta e experimentação da realidade. É desse modo que a realidade (objeto dinâmico) e a realidade representada (objeto imediato) têm uma conexão necessária, que nos impele a vê-las como interligadas. A realidade transcende aquilo que pode ser vislumbrado, para Santaella (1995, p. 34), "ela é experimentada, provada, tocada, por exemplo." O signo se relaciona com seu objeto por meio de uma qualidade, que pode ser interna (ícone), relativa (índice) ou imputada (símbolo).

O presente estudo, realizado durante cursos da disciplina de química orgânica ministrados para alunos de graduação em Química de uma universidade pública, busca identificar e descrever como se estabelecem as relações entre estudantes, professores e as diferentes estratégias de comunicação empregadas no desenvolvimento conceitual dessa temática. Procura-se, também, identificar e interpretar a consecução da Tríade Pedagógica, ou seja, o processo de perceber, relacionar e conceituar os sistemas simbólicos no processo de elaboração conceitual.

$\mathrm{Na}$ perspectiva de uma abordagem semiótica, as representações foram interpretadas considerando-se os níveis de relações (perceber, relacionar, conceituar) estabelecidos pelos signos e efetivados pelos alunos (intérpretes), o que implica observar as relações ou generalizações conceituais emitidas por eles durante suas ações (por exemplo, resolução de exercícios, questões em provas, perguntas em aulas), as quais possibilitam que se observem elementos indicativos do seu pensar. Delimitou-se a sala de aula como núcleo de uma rede de atividades para a formulação de situações de estudo, pois sabe-se que é na sala de aula que o professor determina o conteúdo, a forma e as ferramentas que serão utilizadas nos processos de ensino e aprendizagem de determinado conceito. No decorrer do curso de uma disciplina, são propostos: problemas, exercícios, testes, provas, seminários, situações de estudo, a serem ampliados por atividades que também se prolongam para fora da sala de aula. Portanto, a opção pela sala de aula se justificava, pois ser este locus um meio de intercomunicação no qual o professor apreende as participações de cada aluno em relação a um conjunto de atividades propostas ou negociadas, que são interpretadas como relações entre signos, objetos e interpretantes.

\section{Abordagem metodológica}

O modelo metodológico adotado foi construído a partir de quatro momentos ou tipos de atividades que compuseram a rede de situações de estudo: (i) observação sistemática nas disciplinas de Química dos Compostos Orgânicos I (QCOI) e Química dos Compostos Orgânicos II (QCOII); (ii) estudo das avaliações utilizadas pelos professores em suas disciplinas; (iii) análise das respostas dos alunos às avaliações; (iv) questionário aplicado a professores e estudantes, com duas questões, uma envolvendo os conteúdos relativos ao ensino de química orgânica, e, a outra, envolvendo os conteúdos relativos à noção estrutural em Química.

As informações foram coletadas durante as aulas do curso de Química dos Compostos Orgânicos I (sessenta horas/aula) e Química dos Compostos Orgânicos II (sessenta horas/ aula), a partir: da observação de como as atividades são propostas, da natureza dos eventos 
ocorridos durante as aulas, dos tópicos desenvolvidos, e das ferramentas utilizadas pelos professores durante as aulas (Quadro 1).

Quadro 1. Modelo de mapa de eventos para guiar a observação das aulas

\begin{tabular}{|c|c|c|c|c|c|}
\hline $\mathbf{N}^{\mathbf{0}}$ & Data & $\begin{array}{c}\text { Detalhamento e/ou } \\
\text { temas envolvidos }\end{array}$ & $\begin{array}{c}\text { Natureza do } \\
\text { evento }\end{array}$ & Tópicos & Ferramentas \\
\hline & $\begin{array}{c}\text { Descrição do tema ou } \\
\text { conceitos }\end{array}$ & $\begin{array}{c}\text { Identificação da } \\
\text { natureza de eventos }\end{array}$ & $\begin{array}{c}\text { São conteúdos } \\
\text { abordados }\end{array}$ & $\begin{array}{c}\text { Atividade simbólicas } \\
\text { de caráter }\end{array}$ \\
\hline
\end{tabular}

Fonte: Adaptado de Araújo Neto (2009).

No estudo das avaliações, selecionaram-se cinco grupos de estudantes universitários para análise das provas: três grupos matriculados na disciplina de QCOI e dois grupos matriculados na disciplina de QCOII. Foram disponibilizadas, para este estudo, 254 provas de QCOI e 154 provas de QCOII. Em relação aos questionários, ele foi aplicado a estudantes de seis universidades públicas das regiões Nordeste e Sudeste do Brasil. Responderam, ao questionário, 158 estudantes que estavam cursando ou já tinham cursado a disciplina de Química orgânica II, e trinta professores de química orgânica dessas mesmas instituições.

\section{Resultados}

Neste artigo, por questão de clareza, optou-se por apresentar apenas um dos episódios em que foi possível verificar situações relacionadas a aspectos representacionais que ocorrem na relação triádica entre Perceber-Relacionar-Conceituar, nas sequências didáticas observadas durante os cursos de QCOI e QCOII, a título de exemplo da abordagem que se propõe a partir da reflexão apresentada neste trabalho.

Episódio de n. 05 (06/08/2009): o tema desenvolvido nessa aula foi o de "Características e propriedades dos álcoois". O professor iniciou a aula solicitando que os alunos desenhassem a estrutura do etanol em seus cadernos. Praticamente a totalidade dos alunos representou a substância pelo desenho da molécula de etanol usando, como recurso, a fórmula estrutural (Figura 3A) e, alguns, a fórmula condensada (Figura 3B).

Figura 3A. Representação estrutural para a molécula de etanol, na forma de traços<smiles>CCCC</smiles>

Figura 3B. Representação estrutural para a molécula de etanol, na forma condensada

\begin{tabular}{ccc}
$-\stackrel{\mathrm{C}}{\mathrm{C}}-\mathrm{C}_{-}^{-}$ & \\
$\mathrm{H} \quad \mathrm{H}$ & $\mathrm{CH}_{3} \mathrm{CH}_{2} \mathrm{OH}$ \\
\hline
\end{tabular}

Fonte: construídas pelos autores no software Chem Draw Ultra ${ }^{\circledR}$. 
Após verificar as estruturas construídas, o professor solicitou, aos alunos, que fizessem, também, uma representação da estrutura para a molécula de etanol considerando-a no espaço, ou seja, uma representação 3D (tridimensional), como representado na Figura 4, em que as cunhas tracejadas representam átomos que penetram no plano do papel, enquanto as cunhas em negrito representam aqueles que saem desse plano. Essa representação é convencional e compartilhada pelos químicos orgânicos.

Figura 4. Representação estrutural convencional em 3D para a molécula de etanol

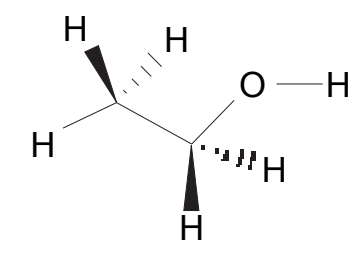

Fonte: construída pelos autores no software Chem Draw Ultra $\AA$.

Como os alunos apresentaram dificuldades em representar a molécula no espaço, o professor apresentou (Perceber) um modelo físico (bola-vareta, vide Figura 5) para que os alunos pudessem visualizar (Relacionar) melhor a estrutura da molécula de etanol (Figura 5) e, neste caso, terem um parâmetro de como desenhá-la em 3D (Conceituar).

Figura 5. Representação estrutural para a molécula de etanol com modelo físico bola-varetas

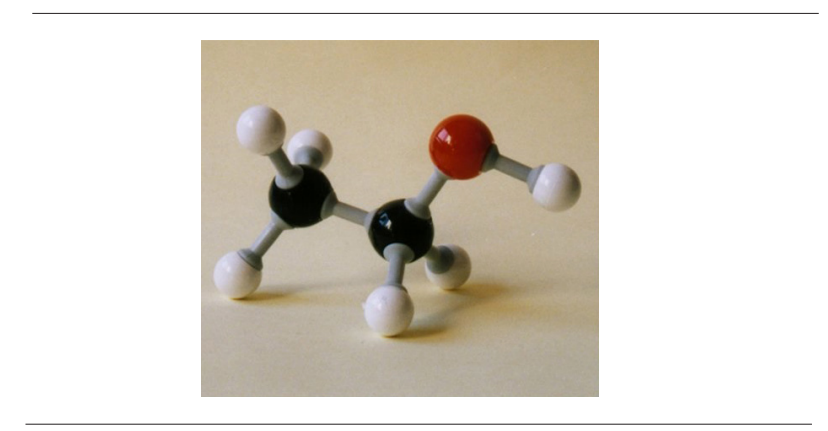

Fonte: construída pelos autores no software Chem Draw Ultra ${ }^{\circledR}$.

O professor fez com que os alunos tentassem desenhar a molécula de diferentes maneiras, mostrando o modelo para eles a partir de diferentes ângulos. O uso do modelo molecular (mostrado na Figura 5) permite, em tese, um aumento da percepção sobre o objeto (objeto dinâmico), sobre o tamanho distinto dos átomos e das ligações entre eles nos modelos 
moleculares que representam a forma da molécula, bem como um aumento da percepção em relação à posição e à distância entre eles no espaço. Após introduzir, neste episódio, atividades de conteúdos espaciais simbólicos, que conjugam habilidades de visualização e de estabelecer relações, o professor começou a discutir e a apresentar propriedades dos álcoois relacionadas às suas estruturas.

O episódio descrito envolve o estabelecimento de relações entre as ferramentas gráficas e ferramentas materiais. Neste caso, a ferramenta material (modelo físico de bola e varetas) serve de mediação para correlacionar as representações gráficas (diagramas, equações desenhadas no quadro ou apresentadas em diapositivos), com o objetivo de promover uma relação de identidade entre as ferramentas utilizadas. Como o professor escolheu empregar diferentes ferramentas na associação de formas simbólicas representativas, considerou-se que houve uma escolha que favorecia o processo de elaboração conceitual, pois diferentes situações foram criadas com a intenção de facilitar a compreensão por meio do emprego de diferentes formas de representação.

Em relação à tríade pedagógica (perceber - relacionar - conceituar), verificaram-se, nos episódios, diferentes situações que favorecem o aumento na percepção e, por conseguinte, o estabelecimento de uma inter-relação mais efetiva entre os fundamentos (representamen, objeto e interpretante) do signo, permitindo novas semioses que podem ser compreendidas como operações produtoras e geradoras de signos, partindo-se do pressuposto de haver relação entre signo, objeto e interpretante, gerando outros signos. Estes signos podem ser interpretados, em aulas de Ciências, como: concepções alternativas, construtos teóricos, novos conceitos que permitem novas relações entre os três elementos da semiótica peirceana, o que torna o processo de semiose infinito.

Por exemplo, no episódio descrito, quando o professor solicita aos alunos que desenhem a estrutura do etanol, esta atividade é importante no sentido de ampliar a informação sobre a estrutura da molécula da substância (objeto) em um processo semiótico. Nesse episódio, foi possível verificar que trabalhar, com os estudantes, o uso de modelos moleculares (bola-vareta ou elaborados com materiais mais simples como palitos e bolas de isopor), ou até incentivar o recurso a modelos virtuais construídos por meio de ferramentas computacionais é fundamental para sua compreensão e elaboração conceitual.

Em relação à análise das provas, optou-se por apresentar, nesta discussão, apenas as questões pertinentes, que tivessem relação com a tríade pedagógica. Verificou-se que, na maioria das questões, as estruturas moleculares são um dos dados apresentados aos estudantes, que são desafiados a identificarem se as estruturas são planares ou não. A análise das respostas dos alunos evidenciou que os estudantes têm dificuldades para perceber determinados aspectos, observando apenas as estruturas no plano do papel, mesmo para compostos aromáticos que são compostos planares. Assim, as estruturas das moléculas, mesmo quando corretas, são apenas estruturas no plano que, na forma de traços (ver Figuras 3A e 6), dificultam a percepção, visualização e compreensão dos mecanismos de reação propostos para as substituições nucleofílicas ao carbono ( $\mathrm{S}_{\mathrm{N}} 1$ e $\mathrm{S}_{\mathrm{N}}$ ), um dos tipos de processo discutidos nos cursos introdutórios de química orgânica. Os estudantes que desenham a estrutura do composto sem considerar a posição relativa no espaço dos grupos substituintes da cadeia principal da molécula têm sua capacidade de percepção da ocorrência ou não de inversão de configuração limitada. Por outro lado, os estudantes que constroem, no plano, as estruturas bidimensionais em forma de cunhas (Figuras 4 e 7) e, por conseguinte, apresentam maior facilidade de visualizar (perceber) espacialmente os 
grupos, podem prever, (relacionar) com maior facilidade, a ocorrência, ou não, da inversão da configuração (conceituar), como se pode concluir ao se comparar, cuidadosamente, as Figuras 6 e 7, que apresentam representações de alunos dos cursos de Química orgânica.

Figura 6. Estrutura planar para os compostos

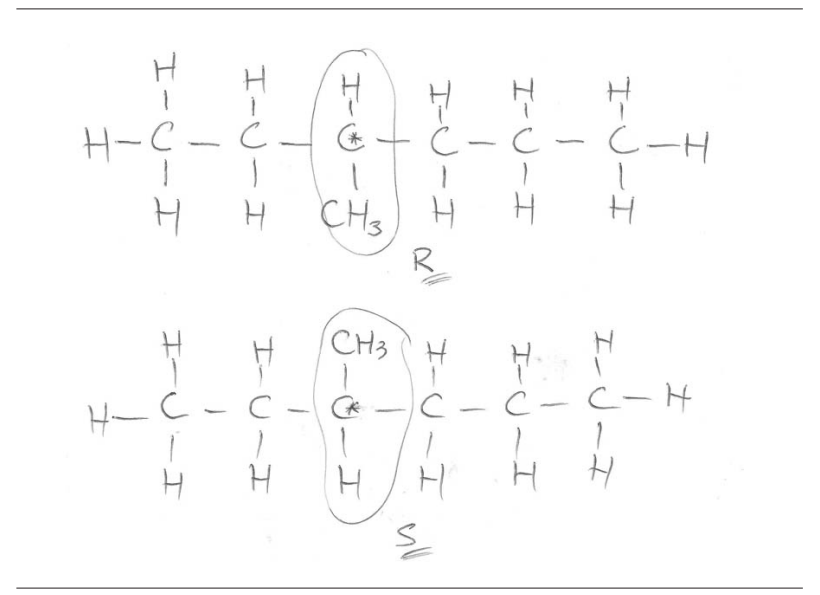

Essa representação dificulta a compreensão do conceito, e a resolução do problema torna-se praticamente impossível, a não ser por algoritmos de memorização de situações semelhantes.

Fonte: extraída da prova dos estudantes.

$\mathrm{Na}$ análise das respostas dos estudantes, verificou-se que, além da dificuldade de percepção de determinadas características na estrutura inicial fornecida pelo professor, esses estudantes apresentam dificuldades na determinação da configuração das moléculas dos produtos formados, ou seja, não apresentam compreensão do conteúdo conceitual contido nas estruturas. Nesse grupo de estudantes, foi possível identificar que cerca de 40\% tinham dificuldades em reconhecer (perceber) os grupos, as ligações e o número de carbonos na estrutura descrita na forma de linhas, fato que foi possível identificar, ainda, no acompanhamento de suas aulas. Como não identificam determinadas características na estrutura da molécula (perceber), o que poderia permitir que realizassem determinadas relações espaciais (relacionar), também foram incapazes de interpretar o fenômeno da inversão de configuração (conceituar), quando este é o caso (S para R), como demonstrado pela análise da Figura 6.

$\mathrm{O}$ processo mais adequado para se responder a esta pergunta envolveria as etapas apresentadas por um grupo minoritário de estudantes $(18 \%)$ em que, primeiro, se constrói uma representação gráfica, identificando o carbono quiral. Só depois, eles realizam a transformação da representação para a forma de linhas angulares, com cunhas indicando a posição relativa dos grupos substituintes no espaço, isto é, indicando os grupos que saem e que entram no plano, podendo, desse modo, identificar mais facilmente os dois isômeros ( $\mathrm{R}$ e $\mathrm{S}$ ), como pode ser observado na Figura 7. 
Figura 7. Múltiplos modos representacionais para o mesmo composto

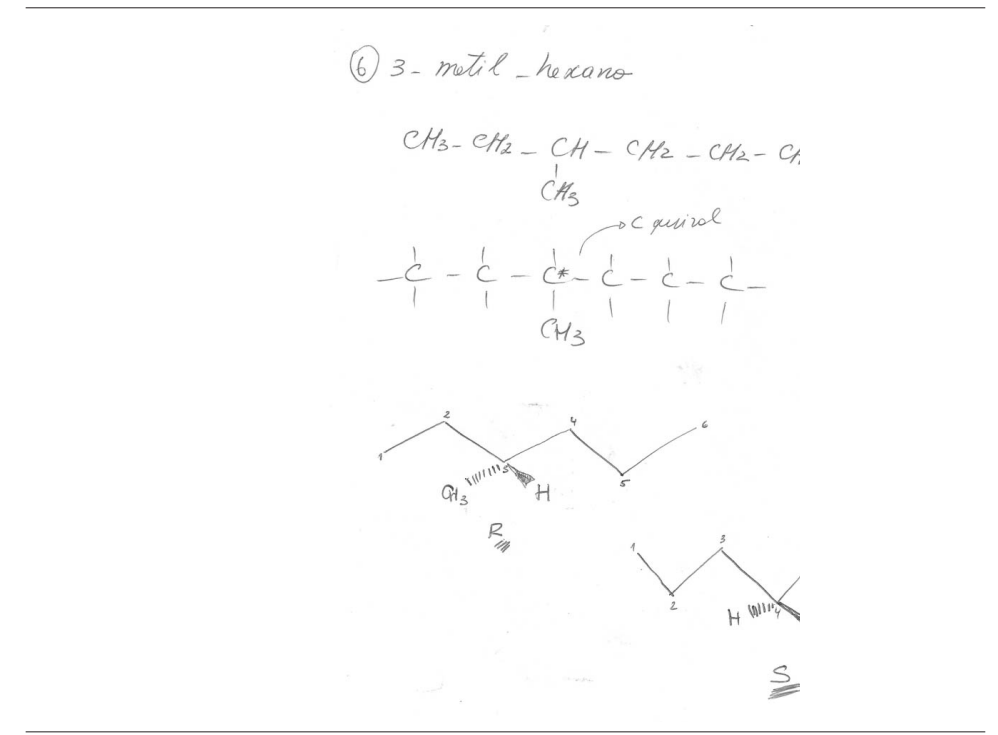

\footnotetext{
Essa representação facilita a compreensão do conceito, possibilitando a resolução do problema.

Fonte: extraída da prova dos estudantes.
}

Diante dos diagramas estruturais, com estruturas tridimensionais (espacialidade), o estudante atuará sobre o problema com uma orientação espacial predeterminada, facilitando o perceber de aspectos fundamentais quanto a efeitos como rotação e inversão sobre as estruturas moleculares. Na Figura 7, é possível verificar como a representação estrutural direcionada para as características espaciais, que são fundamentais no estabelecimento das relações e, consequentemente, para a resolução do problema, permite interpretar a questão mais adequadamente.

Finalmente, a análise das respostas à questão que aborda o papel da representação em química orgânica levou à construção de seis categorias que possibilitaram uma melhor compreensão sobre as diferentes concepções dos estudantes (Tabela 1) e dos professores (Tabela 2) sobre essa temática.

Tabela 1. Categorias das formas de pensar em relação ao papel da representação no Ensino de Química (estudantes)

\begin{tabular}{clc}
\hline Categoria & \multicolumn{1}{c}{$\begin{array}{c}\text { Concepção dos estudantes sobre o papel das } \\
\text { representações no ensino de química orgânica }\end{array}$} & $\begin{array}{c}\text { Estudantes } \\
\mathbf{( \% )}\end{array}$ \\
\hline 1 & Facilitar a visualização de estruturas moleculares & 32 \\
2 & Auxiliar no entendimento dos conceitos e das estruturas moleculares & 25 \\
3 & Dar a posição dos elementos na molécula e do tipo de ligação] & 14 \\
4 & Mostrar a molécula de forma mais didática e mais clara & 12 \\
5 & Trazer uma aproximação mais realista para o conhecimento & 10 \\
6 & Resposta sem sentido ou não respondeu & 7 \\
\hline
\end{tabular}

Fonte: Elaborada pelos autores. 
Tabela 2. Categorias das formas de pensar em relação ao papel da representação no Ensino de Química (professores)

\begin{tabular}{clc}
\hline Categoria & \multicolumn{1}{c}{$\begin{array}{c}\text { Visões dos professores sobre o papel das } \\
\text { representações na química orgânica }\end{array}$} & $\begin{array}{c}\text { Professores } \\
\mathbf{( \% )}\end{array}$ \\
\hline 1 & É a linguagem oficial adotada na química orgânica & 20 \\
2 & Facilitar o processo de ensino e de aprendizagem & 20 \\
3 & Modelos visuais de como as moléculas estão organizadas & 30 \\
4 & Fornecer informações sobre a substância que ela representa & 30 \\
\hline
\end{tabular}

Fonte: Elaborada pelos autores.

Apesar de professores e estudantes apresentarem diferentes visões para o papel da representação no ensino de química orgânica, é possível perceber que todas convergem para um mesmo ponto. As representações são uma forma de linguagem que descreve transformações químicas por meio de modelos, sendo representadas por: fórmulas estruturais, equações, gráficos e figuras. Embora haja esse consenso, é interessante que não se perceba um esforço consciente nas sequências didáticas (episódios de aula) que foram observadas, no sentido de que os alunos viessem a se apropriar dessa linguagem.

\section{Discussão}

Como respostas às questões iniciais da pesquisa, a partir da análise das diferentes fontes de informações, pode-se afirmar que, em relação à tríade pedagógica (Perceber - Relacionar - Conceituar), há uma série de lacunas que precisam ser preenchidas. Em relação ao Perceber (primeiridade), observa-se que os professores, ao utilizarem diferentes estratégias de comunicação, desconsideram os aspectos visuais e representacionais, tão importantes quanto os aspectos conceituais no ensino e na aprendizagem de química orgânica, ou seja, aspectos relacionados à mediação e à representação em aulas de química orgânica são, ainda, pouco valorizados durante as aulas. Verificaram-se, na análise dos episódios, poucas ou quase inexistentes atividades direcionadas, exclusivamente, à abordagem de conteúdos representacionais. Além disso, identificaram-se professores que responsabilizam os estudantes e a própria disciplina pelas dificuldades de aprendizagem, embora tenha sido possível identificar uma pequena parcela de professores que se percebem, também, como causas do problema.

Em relação ao Relacionar (secundidade) e Conceituar (terceiridade), identificou-se, entre os estudantes, uma série de dificuldades para estabelecer as devidas relações entre os signos (Perceber), que são apresentados, pelo professor, na forma de diagramas, esquemas, textos e gráficos (estratégias de comunicação). Assim, há dificuldade dos estudantes na compreensão do conteúdo conceitual contido nas diferentes representações simbólicas (estudantes com baixas habilidades visuoespaciais - que são a maioria - têm inconvenientes para transformar a informação verbal em representação visual). Há dificuldades na compreensão do conteúdo conceitual contido nas representações estruturais, sobretudo dificuldades de conversão, ou seja, de realizar conversões entre diferentes formas de representação para um mesmo composto. 
Dos resultados desta investigação, pode-se claramente defender que a questão do processo de representação, no contexto dos processos de ensino e aprendizagem da química orgânica, é muito mais do que incluir um novo tema ou um novo tópico de conteúdo no programa da disciplina. Considerar os processos de ensino e aprendizagem de conceitos de química orgânica na perspectiva da Semiótica Peirceana requer uma mudança de perspectiva mais geral, em que a representação seja concebida como um sistema de significação, uma forma de atribuição de sentido e de elaboração conceitual. Requer que a sala de aula seja vista como um espaço de relações entre signos, objetos e interpretantes, pois, de acordo com a Semiótica Peirceana, as coisas (objetos moleculares, figuras, desenhos, diagramas, por exemplo) se apresentam e não representam (primeiridade). Para Peirce (2005), os signos são traduzidos como processos de mediação, portanto a representação é o próprio processo de mediação. É o objeto (objeto dinâmico) que gera um signo (objeto imediato) para um interpretante (interpretante dinâmico) ou um novo signo. As estratégias de comunicação (ferramentas gráficas ou computacionais), nessa perspectiva, são utilizadas para ampliar, melhorar ou tornar mais eficiente o processo de percepção sobre o objeto.

Toda percepção adiciona algo novo ao percebido, que pode ser interpretado como um processo de significação ou de compreensão. Daí a necessidade de diferentes estratégias de comunicação (conforme modelo da Figura 8), e do uso de multimodos de representação, de maneira a proporcionar, aos estudantes, possibilidades de construção de múltiplas representações sobre um mesmo objeto. Em síntese, visualizar representações químicas requer a relação cognitiva entre componentes conceituais e componentes visuais que supõem a interpretação de signos.

Figura 8. Representação da tríade pedagógica em uma aula de química orgânica

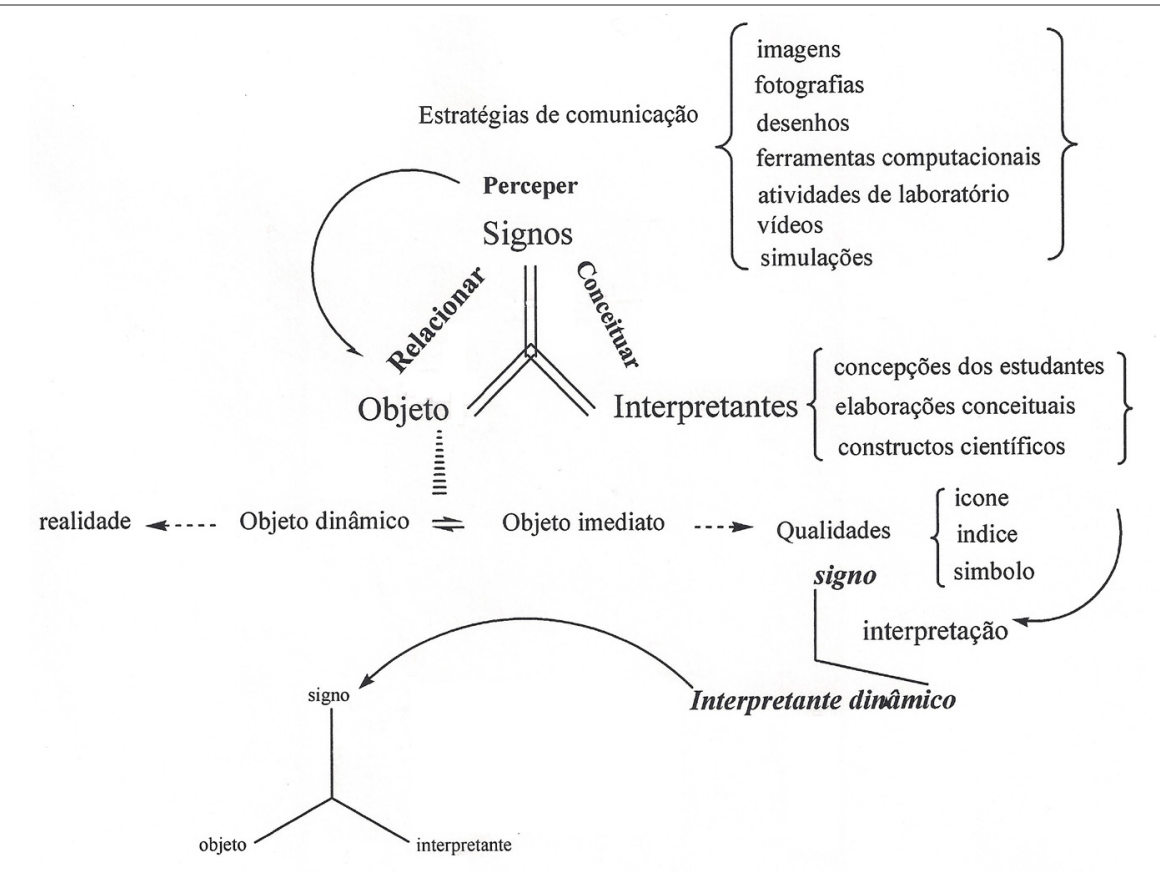

Fonte : adaptada de Souza (2012). 


\section{Conclusões}

A compreensão do processo semiótico na elaboração de construtos científicos leva à necessidade de valorização de aspectos relacionados à mediação nas aulas de química orgânica. Portanto, do ponto de vista dos processos de ensino e aprendizagem, tal disciplina requer uma mudança profunda, que deve ocorrer no âmbito educacional, buscando uma formação que considere ser o corpo teórico da Química construído sobre uma linguagem própria, criada para representar o universo das transformações químicas. As representações gráficas e pictóricas de um mundo abstrato de átomos, íons e moléculas são símbolos que, a todo o momento, estão presentes no enfoque teórico dessa Ciência. As fórmulas químicas, os mecanismos e as equações químicas, além de funcionarem como ferramentas no trabalho do químico, cumprem, também, a função de linguagem, permitindo a mediação e a comunicação de conteúdos.

Em outras palavras, ensinar ou aprender Química significa realizar um trabalho voltado especificamente para a linguagem química, ou seja, trabalhar temáticas, também, relacionadas a aspectos representacionais. Não apenas a incorporação do uso de ferramentas virtuais, modelos físicos de estruturas que abordem questões de habilidades visuoespaciais, mas, acima de tudo, o uso de diferentes estratégias de comunicação em processos de semiose (percepção, relação e conceituação), para que se construam interpretantes dinâmicos que, ao atuarem como novos signos em novas semioses (processos de representação e/ou mediação), atuem como legi-signos (signo convencional) em seu fundamento.

Para tanto, é necessário dar condições em cada espaço e tempo, assim como possibilitar a transformação dessas condições. Significa tratar essas temáticas de forma a contemplar os conhecimentos científicos estabelecidos, enriquecendo o conhecimento. Significa considerar que o estudante percebe os fenômenos e os representa, ou seja, é um preceptor/representador dos fenômenos. Significa, ainda, considerar que as várias representações empregadas para a compreensão de um conceito têm relações entre si. Os signos (símbolos, imagens, diagramas, por exemplo) não podem ser considerados trivialmente inteligíveis e diretamente transparentes para os estudantes.

Portanto, a aprendizagem de conceitos da química orgânica não pode ser separada de como representá-los e do que significam. Toda palavra, figura, diagrama, equação ou simbolismo envolvido por detrás das ações e procedimentos, por exemplo, pertencem a um contexto que é parte de uma troca de significados. Estes significados são construídos e reconstruídos em um processo de semiose.

Por fim, cabe ressaltar que este trabalho se desenvolveu no âmbito teórico, de reflexão, que foi enriquecido por atividades concretas em sala de aula com professores e estudantes de química orgânica. Portanto, cabe, nesse momento, dizer que toda essa reflexão se faz essencial se o intuito é promover, no contexto do ensino de química orgânica, uma mudança efetiva nos discursos levados para a sala de aula e replicados socialmente. Essa mudança não significará somente aceitar e incorporar as diferentes perspectivas oriundas da análise semiótica de aulas de química orgânica, mas implicará, também, uma nova postura frente às questões relacionadas à linguagem no processo de elaboração conceitual. Seria importante que a comunidade de químicos, pelo menos no âmbito acadêmico, se convencesse firmemente de que, afinal, aprender Química é também aprender sobre suas representações. 


\section{Referências}

ARAÚJO NETO, W. N. Formas de uso da noção de representação estrutural no ensino superior de química. 2009. 235 f. Tese (Doutorado em Educação) - Faculdade de Educação, Universidade de São Paulo, São Paulo, 2009.

CHANDRASEGARAN, A.; TREAGUST, D. F.; MOCERINO, M. An evaluation of a teaching intervention to promote students' ability to use multiple levels of representation when describing and explaining chemical reactions. Research in Science Education, Dordrecht, v. 38, n. 2, p. 237-248, 2007.

CHITTLEBOROUGH, G.; TREAGUST, D. F. The modelling ability of non-major chemistry students and their understanding of the sub-microscopic level. Chemistry Education Research and Practice, Cambridge, UK, v. 8, n. 3, p. 274-292, 2007.

HABRAKEN, C. L. Integrating into chemistry teaching today's student's visuospatial talents and skills, and the teaching of today's chemistry's graphical language. Journal of Science Education and Technology, Dordrecht, v. 13, n. 1, p. 89-94, 2004.

. Perceptions of chemistry: why is the common perception of chemistry, the most visual of sciences, so distorted? Journal of Science Education and Technology, Dordrecht, v. 5, n. 3, p. 193-201, 1996.

JOHNSTONE, A. H. The development of chemistry teaching: a changing response to changing demand. Journal of Chemical Education, Washington, v. 70, n. 9, p. 701-705, 1993.

. Macro and micro-chemistry. School Science Review, Hatfield, UK, v. 64, n. 227, p. 377- 379, 1982.

Teaching of chemistry: logical or psychological? Chemistry Education Research and Practice, Cambridge, UK, v. 1, n. 1, p. 9-15, 2000.

You can't get there from here. Journal of Chemical Education, Washington, v. 87, n. 1, p. 22-29, 2010.

JORGE, A. M. G.; REZENDE, D. B.; WARTHA, E. J. Visualização, semiótica e teoria da percepção. Tríade: comunicação, cultura e mídia, Sorocaba, v. 1, n. 1, p. 149-166, 2013.

KLEINMAN, R. W.; GRIFFIN, H. C.; KERNER, N. K. Images in chemistry. Journal of Chemical Education, Washington, v. 64, n. 9, p. 766-770, 1987.

LABARCA, M. Acerca del triangulo de Johnstone: algunos comentarios filosóficos. In: CONFERÊNCIA LATINO-AMERICANA DO INTERNATIONAL HISTORY, PHILOSOPHY AND SCIENCE TEACHING GROUP, 1., 2010, Maresias. Caderno de resumos... São Paulo: USP, 2010. p. 101.

PEIRCE, C. S. Semiótica. 8. ed. São Paulo: Perspectiva, 2005. (Coleção Estudos. Semiótica, 46). 
Wartha, E. J.; Rezende, D. B.

RAPPOPORT, L. T.; ASHKENAZI, G. Connecting levels of representation: emergent versus submergent perspective. International Journal of Science Education, Abingdon, v. 30, n. 12, p. 1585-1603, 2008.

SANTAELLA, L. Percepção: fenomenologia, ecologia, semiótica. São Paulo: Cengage Learning, 2012.

SOUZA, K. A. F. D. Estratégias de comunicação em química como índices epistemológicos: análise semiótica das ilustrações presentes em livros didáticos ao longo do século XX. 2012. 189 f. Tese (Doutorado em Química) - Instituto de Química, Universidade de São Paulo, São Paulo, 2012.

TALANQUER, V. Macro, submicro, and symbolic: the many faces of the chemistry "triplet". International Journal of Science Education, Abingdon, v. 33, n. 2, p. 179-195, 2011.

TREAGUST, D. F.; CHITTLEBOROUGH, G.; MAMIALA, T. L. The role of submicroscopic and symbolic representations in chemical explanations. International Journal of Science Education, Abingdon, v. 25, n. 11, p. 1353-1368, 2003.

Artigo recebido em 18/02/14. Aceito em 16/07/14. 